\title{
Instalación de una planta procesadora de extruido de una mezcla de cañihua y tarwi: Estudio preliminar
}

\author{
Bruno H. Weitz Perl \\ Ingeniería Industrial n. 27, 2009, ISSN 1025-9929, pp. 207-234
}

RESUMEN: La demanda mundial de productos naturales que ayudan a reducir los niveles de colesterol y prevenir las enfermedades cardiovasculares viene creciendo de modo sustancial. La cañihua y el tarwi, alimentos peruanos de alto valor nutritivo, al mezclarse, conforman un producto altamente proteico, que además tiene un alto contenido de fibra dietética. Esto, unido a las múltiples ventajas que presenta la tecnología de la extrusión para la industria alimentaria y a la creciente preocupación de la sociedad por consumir alimentos sin aditivos químicos, da lugar a un proyecto ambicioso que se une a la tendencia creciente de exportación de productos de alto valor agregado, los cuales constituyen una fuente importante de ingreso de divisas al país, así como una provisión de trabajo digno a miles de personas.

Palabras clave: productos orgánico-funcionales / cañihua / tarwi / extrusión / comercio justo

\section{Installation of a processing plant of an extruded mixture based on cañihua and tarwi: Preliminary study}

\begin{abstract}
Global demand for natural products that help reduce cholesterol levels and prevent cardiovascular diseases have been showing a big growth in the last years. Cañihua and tarwi, both high-nutritional-value Peruvian foods, when mixed, produce a high-protein product that also has a high content of dietary fiber. This fact, attached with the many advantages of the extrusion technology for food industry and the growing concern of the society for eating food without chemical additives, results in an ambitious project that joins the growing trend of high-value-added products for export, which constitute an important source of foreign income to the country, as well as a provision of decent work for thousands of people.
\end{abstract}

Keywords: organic and functional products / cañihua / tarwi / extrusion / fair trade 


\section{INTRODUCCIÓN}

De un tiempo a esta parte, las sociedades, en el ámbito mundial, están cambiando paulatinamente sus hábitos alimenticios. Se puede identificar una mayor preocupación por la salud personal y familiar, por lo cual las personas vienen modificando (algunas de manera estructural) sus vidas; han comenzado a practicar deportes, a reducir o incluso eliminar el consumo de cigarro y bebidas alcohólicas, y, sobre todo, ponen atención en los alimentos que consumen. En estos tiempos, no es extraño que los consumidores se interesen por los ingredientes que contiene todo lo que ingieren, la información nutricional de ello y los beneficios y amenazas que representa para su organismo.

Según la OMS, en todo el mundo hay alrededor de 1.300 millones de personas con problemas de obesidad, 600 millones tienen contrariedades con su presión arterial y 150 millones sufren de diabetes. Por esta razón, la industria alimentaria ha encontrado un nuevo nicho en apogeo: el de la comida que procure la salud de sus consumidores. De esta manera, la alimentación saludable se está convirtiendo en una de las industrias más promisorias del mundo.

La antigua idea popular de que la comida es la mejor medicina es apoyada cada vez más por la ciencia. La imparable penetración de los alimentos funcionales revela que dentro de algunos productos (naturales o elaborados) se encuentra de manera intrínseca una eficaz "medicina". Se come, entonces, ya no solo para nutrirse, sino para prevenir o tratar con alimentos específicos las enfermedades o dolencias que amenazan.

El Perú ofrece múltiples alternativas que pueden satisfacer las diversas necesidades de estas personas. Entre ellas, una amplia gama de cereales y leguminosas que se cultivan en el país desde tiempos milenarios. En ese sentido, las culturas preínca e inca ya conocían las bondades de la quinua, la cañihua, la kiwicha, la maca, el tarwi, entre otros productos que les daban altas proporciones de proteínas, vitaminas y minerales. Algunos productos sobrevivieron a la conquista española y ahora son ampliamente reconocidos en el territorio nacional e internacional; sin embargo, la suerte de otros fue distinta al reducirse considerablemente sus áreas de siembra, conservándose gracias al afán de algunos campesinos, quienes los siguen cultivando casi exclusivamente para su consumo personal. 


\section{OBJETIVOS DEL PROYECTO}

De las constataciones que se reseñan en párrafos anteriores, surge la idea de este estudio, que tiene como finalidad analizar la viabilidad técnica y económica de la implementación de una planta productora de extruido de una mezcla de cañihua y tarwi, cereal y leguminosa, respectivamente, oriundas del Perú, para obtener un producto de calidad internacional. Se trata, finalmente, de contribuir al desarrollo agrícola y agroindustrial de las zonas más desfavorecidas del país, así como reposicionar y promocionar estos productos dentro y fuera de nuestras fronteras. La concreción del proyecto permitiría proveer alimentos funcionales sabrosos y de gran valor nutritivo, que mejorarían la calidad de vida de la población.

En línea con lo anterior, se buscará alcanzar los siguientes resultados:

- Un margen bruto no menor al 45\% en el tercer año de operaciones.

- Una participación de mercado superior al 1\% en los países donde se inicien operaciones en el quinto año luego de la puesta en marcha.

- Un nivel de ventas de 2.000 toneladas anuales a partir del año 2013.

- Mantener un nivel de servicio por encima del 90\% durante toda la vida útil del proyecto.

- Destinar el 2\% de las inversiones anuales a programas de responsabilidad social en las comunidades campesinas donde el proyecto tenga injerencia.

Resumiendo los aspectos cualitativos, el proyecto persigue:

- Aprovechar de manera óptima los recursos naturales con los que cuentan los Andes peruanos, revalorando los cultivos tradicionales y promoviendo su desarrollo sustentable, siguiendo las ideas básicas del conservacionismo.

- Posicionar la cañihua y el tarwi en la mente de los consumidores como una excelente alternativa nutritiva y funcional, dando a conocer sus múltiples ventajas comparativas respecto a los alimentos industriales de menor valor nutritivo. 
- Impulsar la idea de invertir en el agro tecnificado para rescatar los cultivos nacionales reemplazados y olvidados, con la finalidad de lanzar al mercado productos altamente beneficiosos para la salud humana mundial.

- Promocionar el Perú a través de sus únicos y excepcionales productos, mediante su exportación planificada.

\section{ESTUDIO DE MERCADO}

\subsection{Demanda del proyecto}

Para determinar la demanda que podría tener este proyecto, se realizó un análisis del consumo de cereales listos para consumir (ready-to-eat cereals - RTEC, por sus siglas en inglés), así como de la ingesta de productos orgánicos y funcionales en el ámbito mundial. Así, se identificó que tanto los mercados de la Unión Europea como los de Norteamérica serían potenciales consumidores del producto que este proyecto ofrecería. Posteriormente, se evaluó el consumo per cápita de cereales RTE que tenían los países de estas regiones, considerando también la proporción de alimentos orgánicos que adquiere su población. De esta manera, se decidió apostar por dos mercados en crecimiento en lo que a productos orgánicos se refiere, en el rubro de cereales listos para consumir: el Reino Unido y Canadá. ${ }^{1}$

Para calcular la demanda, se consideró una tasa conservadora del $10 \%$ de crecimiento en lo que respecta al incremento del consumo de productos orgánicos en el mundo, a pesar de que organizaciones como la Organic Trade Association (OTA) y diversos estudios de mercado de

1 El criterio de selección fue el análisis de la información de producción, importaciones y consumo registrados por dichos países en los últimos años, así como el relativo alto consumo per cápita que presenta cada uno, todos ellos en evidente crecimiento. Asimismo, se corroboró que ambos países habían crecido su participación mundial en el lanzamiento de productos relacionados (cereales para el desayuno orgánicos/naturales y/o funcionales) en los últimos años. Finalmente, la lectura de varios textos corroboró que dichos mercados tenían una clara tendencia alcista en lo que a consumo de productos orgánicos se refiere, incluidos los cereales listos para consumir. Sin perjuicio de ello, podría analizarse la inclusión en el mediano plazo del mercado estadounidense, considerando que el A/V de la partida arancelaria 19041000 (productos a base de cereales obtenidos por inflado o tostado) fue eliminada completamente el 1 de febrero del presente año, fecha en el que el TLC Perú-EE.UU. entró en vigencia. 
universidades europeas proyectan un crecimiento mayor al 20\%. Del mismo modo, se tomó en cuenta una tasa de crecimiento anual del $0,88 \%$ y $0,28 \%^{2}$ de la población total ${ }^{3}$ de Canadá y el Reino Unido, respectivamente.

De esta forma, la demanda proyectada para un horizonte de 10 años, recomendada por los expertos, con una pequeña participación de mercado de alrededor del 1\% en los países en los que se participará, limitado por el factor tecnología, como se verá más adelante, queda de la siguiente manera:

\section{Cuadro 1}

Demanda proyectada (2009-2015)

\begin{tabular}{|c|c|c|c|c|c|c|c|}
\hline \multirow[t]{2}{*}{ País } & \multicolumn{7}{|c|}{ Año } \\
\hline & 2009 & 2010 & 2011 & 2012 & 2013 & 2014 & 2015 \\
\hline \multicolumn{8}{|l|}{ Canadá } \\
\hline \multicolumn{8}{|l|}{ Consumo per cápita (cpc) } \\
\hline RTEC (kg/hab./año) & 4 & 4 & 4 & 4 & 4 & 4 & 4 \\
\hline Población total (miles hab.) & 33.034 & 33.325 & 33.618 & 33.914 & 34.212 & 34.514 & 34.817 \\
\hline Consumo anual RTEC (t/año) & 132.137 & 133.300 & 134.473 & 135.656 & 136.850 & 138.054 & 139.269 \\
\hline \multicolumn{8}{|l|}{ Consumo regular anual } \\
\hline alimentos orgánicos $(\%)$ & $42 \%$ & $47 \%$ & $51 \%$ & $56 \%$ & $62 \%$ & $68 \%$ & $75 \%$ \\
\hline Consumo anual RTEC orgánicos (t/año) & 56.083 & 62.234 & 69.060 & 76.634 & 85.040 & 94.367 & 104.717 \\
\hline Participación de mercado (\%) & $0,8 \%$ & $0,8 \%$ & $0,7 \%$ & $0,6 \%$ & $1,1 \%$ & $1,0 \%$ & $0,9 \%$ \\
\hline Demanda para el proy. (t/año) & 466 & 467 & 469 & 471 & 945 & 948 & 952 \\
\hline \multicolumn{8}{|l|}{ Reino Unido } \\
\hline \multicolumn{8}{|l|}{ Consumo per cápita (cpc) } \\
\hline RTEC (kg/hab./año) & 6 & 6 & 6 & 6 & 6 & 6 & 6 \\
\hline Población total (miles hab.) & 61.121 & 61.292 & 61.464 & 61.636 & 61.809 & 61.982 & 62.155 \\
\hline Consumo anual RTEC (t/año) & 366.727 & 367.754 & 368.784 & 369.817 & 370.852 & 371.891 & 372.932 \\
\hline $\begin{array}{l}\text { Consumo regular anual alimentos } \\
\text { orgánicos (\%) }\end{array}$ & $24 \%$ & $26 \%$ & $29 \%$ & $32 \%$ & $35 \%$ & $39 \%$ & $42 \%$ \\
\hline Consumo anual RTEC orgánicos (t/año) & 87.861 & 96.917 & 106.907 & 117.927 & 130.083 & 143.492 & 158.284 \\
\hline Participación de mercado (\%) & $0,8 \%$ & $0,8 \%$ & $0,6 \%$ & $0,6 \%$ & $1,1 \%$ & $1,0 \%$ & $0,9 \%$ \\
\hline Demanda para el proy. (TM/año) & 730 & 728 & 726 & 724 & 1.445 & 1.442 & 1.439 \\
\hline Demanda total (TM/año) & 1.195 & 1.195 & 1.195 & 1.195 & 2.390 & 24 & 2.390 \\
\hline
\end{tabular}

Fuente: Estadísticas FAO, Trade Map, Annual Demographic Statistics 2003 y 2005. <www.indexmundi. com/es>, Organic Trade Association (<www.ota.com>).

2 Datos extraídos del portal: http://www.indexmundi.com/es/

$3 \mathrm{Al}$ ofrecer un producto dirigido principalmente a niños, quizás hubiese sido más adecuado proyectar la demanda en base a la población de 5 a 14 años de edad en cada país. 
La estrategia de este proyecto será hacer crecer el mercado, enfocando todos los esfuerzos de mercadeo en marcar la diferencia respecto a los productos convencionales (no se buscará, por lo tanto, arrebatar mercado a las empresas existentes, ya que están sólidamente posicionadas).

El cereal deberá expenderse a las personas que se preocupan por su salud y la de los suyos, que exigen productos saludables y de alta calidad, que no solo los nutra sino que también les otorgue algún valor agregado, como lo ofrecen los alimentos funcionales. En línea con lo anterior, los niños y jóvenes de estos países desarrollados vienen mostrando preocupación por la sociedad y el medio ambiente, por lo que exigen, cada vez en mayor medida, productos libres de químicos desde su cultivo y proceso de producción; es decir, productos orgánicos.

De acuerdo con lo analizado, y apoyándose en una pequeña encuesta internacional realizada vía electrónica, el grupo poblacional en el que se enfocaría principalmente este proyecto sería el de niños en edad escolar (de 5-14 años) de los países seleccionados para la etapa inicial. No obstante, el producto bien podrá ser consumido por los otros grupos poblacionales existentes, dados los beneficios comparativos que este ofrece versus la oferta actual de productos.

\subsection{Competidores}

Si bien tanto en Canadá como en el Reino Unido el mercado de cereales listo para consumir se encuentra en su etapa de madurez, este sigue siendo dinámico. A su vez, el mercado de productos orgánicos se encuentra aun en la etapa de crecimiento. En ese sentido, distintas marcas de empresas transnacionales y locales (algunas marcas propias pertenecientes a las grandes tiendas retail de cada país) vienen lanzando productos nuevos al mercado cada año. Solo en el 2008, Canadá lanzó 106 nuevos RTEC, de los cuales 28 ingresaron al mercado aduciendo que son orgánicos y 13 lo hicieron bajo el claim de funcionalidad. En el Reino Unido la situación es similar: de los 104 lanzamientos de cereales RTE, 35 son orgánicos y 14 tienen algún beneficio funcional. ${ }^{4}$

4 Los lanzamientos incluyen nuevas variedades y nuevas formulaciones y presentaciones. Fuente: Mintel GNPD (Global New Products Database [Base de Datos Global de Nuevos Productos]). <http://www.gnpd.com/>. 
Algunas de las principales marcas participantes en estos mercados son: Nestlé, Kellogg's, Weetabix, Muddy Cook y Alara.

\subsection{Cereal listo para consumir}

El producto que se comercializará será un alimento saludable, altamente nutritivo, orgánico, funcional y con delicioso sabor, dirigido básicamente al mercado infantil. El RTE será, por tanto, el extruido de una mezcla nutritiva en base a cañihua y tarwi, cuyo valor alimenticio se ve complementado con los beneficios de la lúcuma, que le dará un sabor especial y nuevo para esta categoría. El producto podrá ser consumido en cualquier momento del día, aunque es recomendable que se ingiera en el desayuno, ya que proveerá las proteínas, calorías, vitaminas y minerales esenciales para empezar el día con la energía necesaria. Igualmente, podrá consumirse a lo largo de la mañana, a la hora del lonche o en la noche para revitalizarse luego de realizar todas las actividades diarias. Inicialmente, se ofrecerá solo en envases personales de 22 gramos.

Estudios cuantitativos y cualitativos muestran que los consumidores regulares de productos orgánicos o funcionales en los países donde tendría injerencia el presente proyecto estarían dispuestos a pagar un sobreprecio por esta clase de alimentos. No obstante, cabe señalar que la creciente demanda por estos productos y una efectiva respuesta por parte de las empresas participantes de la categoría, a través de la progresiva diversificación de su oferta, han logrado disminuir los niveles de precio, llegando en la actualidad a estar casi a la par con los alimentos convencionales (no orgánicos).

\section{MATERIAS PRIMAS E INSUMOS PRINCIPALES}

Los insumos principales del producto que ofrecerá el proyecto son cañihua y tarwi (lupino o chocho).

\subsection{La cañihua}

La cañihua (kañiwa o qañawa, como también se le conoce) es un grano alimenticio domesticado, mejorado y consumido por las culturas preíncas e inca de la zona andina, desde, por lo menos, mil años a.C. 
En la Colonia y en gran parte de la República su uso fue restringido y marginal porque se desconocían sus valores nutritivos.

Su alto valor nutritivo y sus propiedades medicinales han contribuido a que la cañihua sobreviva a pesar de las desfavorables circunstancias socioeconómicas. El grano es una importante fuente de proteínas y tradicionalmente ha sido una fuente alternativa vital para la carne y los productos lácteos en las áreas rurales de los Andes. Su composición balanceada de aminoácidos es similar a la composición de la proteína de la caseína de la leche y, tradicionalmente, se usa en mezclas para el destete gradual de los infantes. El grano también tiene alto nivel de fibra dietética, hierro, grasas no saturadas y azúcar.

Cuadro 2

Contenido de minerales en la cañihua

\begin{tabular}{lc}
\hline Minerales & $\begin{array}{c}\mathbf{m g} / \mathbf{g} \text { de } \\
\text { materia seca }\end{array}$ \\
\hline Fósforo & 375 \\
Calcio & 110 \\
Hierro & 15 \\
\hline
\end{tabular}

Fuente: Morón, en Guerra Miranda, Miriam Isabel, 1999.

Cuadro 3

Composición nutricional de la cañihua en comparación con el arroz y el trigo

\begin{tabular}{lcrr}
\hline Componente & Cañihua(a) & Arroz(b) & Trigo(b) \\
\hline Proteínas & 14,00 & 6,20 & 8,60 \\
Grasas & 4,30 & 0,80 & 1,50 \\
Carbohidratos & 64,00 & 76,90 & 73,70 \\
Fibra & 3,80 & 0,30 & 3,00 \\
Ceniza & 4,92 & 0,60 & 1,65 \\
Humedad & 11,12 & 15,45 & 14,08 \\
Total & 100,00 & 100,00 & 100,00 \\
\hline
\end{tabular}

Fuente: (a) Morón, en Guerra Miranda, María Isabel, 1999 y (b) FAO. 


\section{Cuadro 4}

Contenido de los cuatro aminoácidos esenciales en la cañihua en comparación con los del arroz y del trigo (mg. de aminoácidos/g de proteínas)

\begin{tabular}{lccc}
\hline Aminoácidos & Cañihua(a) & Arroz(b) & Trigo(b) \\
\hline Lisina & 59,00 & 26,00 & 29,00 \\
Metionina & 16,00 & 15,00 & 15,00 \\
Treonina & 47,00 & 24,00 & 29,00 \\
Triptófano & 9,00 & 10,00 & 11,00 \\
\hline
\end{tabular}

Fuente: (a) Moron, en Guerra Miranda, María Isabel, 1999 y (b) FAO.

Su cultivo se relaciona directamente con las zonas agroecológicas sunialtiplano y puna, caracterizadas por bajas temperaturas. Alrededor de un $80 \%$ (6.500 hectáreas, aproximadamente) se cultiva en las planicies del altiplano peruano, sobre todo en los departamentos de Cusco y Puno, a unos 3.800 metros de altitud; la zona de mayor producción se concentra al norte del lago Titicaca.

Se estima que hasta la década de 1940 el área sembrada superaba las 10.000 hectáreas, que fueron desplazadas por la cebada y la avena forrajera. Con el tiempo, ello se ha venido revirtiendo, y se han difundido sus cualidades nutritivas, posicionándola como fuente de aminoácidos, hierro y fibra dietética.

La cañihua es altamente resistente a las sequías, sin embargo, una vez que alcanza el estado de ramificación (de 40 a 50 días después de la germinación) requiere de una adecuada humedad, sobre todo durante los primeros 20 días después de este período. Asimismo, todos los genotipos investigados son indiferentes a las condiciones de luz solar.

Además, es inmune a las heladas (puede germinar a $5^{\circ} \mathrm{C}$ y florecer a los $10^{\circ} \mathrm{C}$; las semillas maduran a los $15^{\circ} \mathrm{C}$ y las plantas adultas son resistentes al frío nocturno) y puede resistir ambientes relativamente cálidos, de alrededor de $25^{\circ} \mathrm{C}$, si cuenta con la humedad necesaria. Muestra cierta tolerancia a los suelos salinos, puede cultivarse en suelo con $\mathrm{pH}$ que varía entre 4.8 y 8.5 ; igualmente, no necesita muchos cuidados en el campo pero su cosecha y procesamiento son laboriosos.

La siembra es, usualmente, al voleo, con semillas no seleccionadas y usando varios tipos mezclados; no obstante, estas también pueden 
ser plantadas utilizando equipos mecánicos. Dependiendo de la variedad, la planta tarda entre 95 y 150 días en crecer y madurar. En condiciones naturales se observa un rendimiento del orden de los 2.400 kilos de semilla por hectárea, aunque en ciertas zonas se han obtenido rendimientos de $5.000 \mathrm{~kg} / \mathrm{h}$.

Este cereal andino presenta una dehiscencia (caída del grano) variable, con la cual se confirma que es un cultivo en proceso de domesticación. La pérdida de granos antes y durante la madurez puede alcanzar en algunos ecotipos hasta un 30\% de la producción total. Selecciones efectuadas en la Estación Experimental de Illpa, en Puno, muestran que en el ecotipo Saiwa disminuye esta característica. Sus semillas tienen aproximadamente un milímetro de diámetro y poseen una cubierta rugosa. Estas varían en color desde el marrón oscuro al negro.

De otro lado, la cañihua es una de las plantas más resistentes a las enfermedades debido al ambiente donde esta se desarrolla, pero si se le saca de su hábitat esta podría sucumbir a las pestes y enfermedades.

El tamaño de la planta de la cañihua varía de 20 a $70 \mathrm{~cm}$. La variación de forma y colores sigue un patrón muy semejante al de la quinua. Se han identificado alrededor de 380 tipos en Puno y estos se encuentran en etapa de evaluación. Sin embargo, se han podido diferenciar cuatro factores principales de variación:

- El crecimiento de la planta que puede ser de porte erguido y poco ramificado (Saiwa) o de tipo algo postrado y muy ramificado desde la base (Lasta).

- La coloración del tallo y el follaje: amarillo, verde, anaranjado, rosado, rojo o púrpura.

- El color de las vesículas: blanco o rosado.

- El color y tamaño de las semillas: negro, castaño o castaño claro.

Una ventaja que tiene con respecto a la quinua (cereal andino con la que por mucho tiempo se confundió), es que sus granos contienen un bajo nivel de saponinas, lo que hace que su sabor no sea tan amargo.

En la cocina tradicional, el grano es a menudo convertido en harina de cañiwaco, que se puede consumir con azúcar, leche o agua, añadido a sopas o mezclado con harina de trigo para hacer pan, fideos, pasteles o bocadillos (snacks). Esta puede ser consumida por personas alérgicas al gluten. 
La cañihua tiene también propiedades medicinales: su semilla pulverizada disuelta en agua y vinagre se usa para tratar la tifoidea y el cañiwaco tostado es considerado efectivo contra el mal de altura y la disentería. Adicionalmente, la ceniza de sus tallos y troncos puede usarse como repelente contra insectos. Asimismo, los pobladores de la alta montaña andina, peruanos y bolivianos, queman los residuos del grano trillado y usan la ceniza para hacer llipta, una pasta rica en calcio que se usa para mascar las hojas de coca.

Es una constante que en los primeros meses de cada campaña agrícola (de septiembre a diciembre) se efectúe la siembra de cañihua. Igualmente, la cosecha de este cereal posee una marcada estacionalidad (marzo a junio). En abril se concentra más del $70 \%$ de la campaña anual.

Alrededor del $20 \%$ de la producción de cañihua está siendo utilizada por empresas que ya descubrieron las bondades de este cultivo andino o bien por centros de investigación. Por lo tanto, se tendría el 80\% de la producción restante disponible, es decir, alrededor de 3.700 toneladas. ${ }^{5}$

\subsection{El tarwi}

El tarwi, chocho o lupino andino, es una leguminosa domesticada y cultivada por los antiguos pobladores de la región andina central desde épocas preincaicas, habiéndose encontrado semillas en tumbas de la cultura Nazca y representaciones en la cerámica Tiahuanaco. La planta tiene una altura que oscila entre los 0,4 y 2,0 metros, siendo lo normal un aproximado de un metro.

Las semillas son excepcionalmente nutritivas: las proteínas y el aceite constituyen más de la mitad de su peso. Un estudio realizado en 300 diferentes genotipos de semillas muestra que la proteína contenida varía de $41 \%$ a $51 \%$, mientras que el aceite, cuyo contenido es inversamente proporcional a la cantidad de proteína, varía de $24 \%$ a $14 \%$. Quitándole la cáscara a la semilla y moliendo el grano se obtiene una harina constituida por $50 \%$ de proteínas. La proteína del tarwi contie-

5 Cuando se realizó el trabajo no se constató qué porcentaje de este volumen disponible efectivamente está certificado como orgánico. 
ne cantidades adecuadas de lisina y cistina, aunque posee solo 23 a $30 \%$ de metionina.

El aceite de tarwi es de color claro, que lo hace aceptable para el uso doméstico. Es similar al aceite de maní y relativamente rico en ácidos grasos no saturados, incluyendo el ácido linoleico. El contenido de fibra de la semilla no es excesivo, pero se estima que pueda constituir una fuente importante de minerales.

A continuación se presenta un cuadro con información de los componentes del tarwi en tres distintas presentaciones (cocido con cáscara, crudo sin cáscara y en harina):

Cuadro 5

Composición por 100 gramos de porción comestible de tarwi

\begin{tabular}{lccr}
\hline Componentes & $\begin{array}{c}\text { Tarwi } \\
\text { cocido con } \\
\text { cáscara }\end{array}$ & $\begin{array}{c}\text { Tarwi } \\
\text { crudo sin } \\
\text { cáscara }\end{array}$ & $\begin{array}{c}\text { Tarwi } \\
\text { harina }\end{array}$ \\
\hline Energía (Kcal) & 151 & 277 & 458 \\
Agua (g) & 69,7 & 46,3 & 37 \\
Proteína (g) & 11,6 & 17,3 & 49,6 \\
Grasa (g) & 8,6 & 17,5 & 27,9 \\
Carbohidratos $(\mathrm{g})$ & 9,6 & 17,3 & 12,9 \\
Fibra (g) & 5,3 & 3,8 & 7,9 \\
Ceniza (g) & 0,6 & 1,6 & 2,6 \\
Calcio (mg) & 30 & 54 & 93 \\
Fósforo (mg) & 123 & 262 & 440 \\
Hierro (mg) & 1,4 & 2,3 & 1,38 \\
Tiamina (mg) & 0,01 & 0,6 & - \\
Riboflavina (mg) & 0,34 & 0,4 & - \\
Niacina (mg) & 0,95 & 2,1 & - \\
Acido ascórbico & - & 4,6 & - \\
\hline
\end{tabular}

Fuente: <www.agualtiplano.net/biodiversidad/cultivos/tarwi.htm>.

El tarwi tiene en sus raíces nódulos donde se encuentran bacterias Rhizobium lupini. Estas tienen la propiedad de fijar el nitrógeno de la atmósfera en el suelo; las plantas pueden utilizar este nitrógeno como abono natural. 
$\mathrm{Su}$ centro de origen estaría ubicado en la región andina de Ecuador, Perú y Bolivia, ya que en ella se encuentra la mayor variabilidad genética. Se cultiva principalmente en las zonas templadas-frías (desde Venezuela hasta la zona norte de Chile y Argentina) en valles interandinos y altiplanos. Desde Colombia hasta Bolivia, esta especie crece a altitudes que van desde los 800 metros hasta por encima de los 3.000 m. En Australia, Europa y California ha crecido cerca del nivel del mar. En el Perú crece en zonas de Cajamarca, Ancash, Ayacucho, Cusco, Puno y el Valle del Mantaro.

El tarwi se produce entre abril y diciembre (La Libertad, Cusco y Puno concentran alrededor del 60\% de la producción del país), aunque existe una concentración de disponibilidad en diversos períodos del año por zonas. Así, en la sierra central y sur del Perú se cosecha durante el primer semestre del año, y en la costa, la sierra norte y la selva en el segundo semestre. La producción anual bordea las 8.400 toneladas al año.

Es susceptible al exceso de humedad y moderadamente susceptible a la sequía durante la floración y el envainado. No tolera las heladas en la fase de formación del racimo y la madurez, aunque algunos ecotipos cultivados a orillas del lago Titicaca tienen una mayor resistencia al frío. Prefiere suelos francos y franco-arenosos, con balance adecuado de nutrientes y buen drenaje, y pH que oscila entre 5 y 7 .

Las vainas o legumbres corresponden a los frutos que el ser humano puede consumir. Estas miden de 5 a $10 \mathrm{~cm}$ de largo y contienen de 2 a 6 semillas ovaladas de 0.6 a $1 \mathrm{~cm}$ de diámetro. Cada vaina contiene semillas parecidas al fríjol, las cuales son blancas, moteadas, jaspeadas o negras. El número promedio de vainas por planta es muy variable y puede fluctuar entre 10 y 80 .

Durante la fase de elongación de las vainas, el peso promedio de los granos permanece muy bajo. Posteriormente, una vez que las vainas alcanzan su máxima longitud, este se va incrementando rápidamente en forma lineal. Los granos permanecen verdes hasta un estado próximo a la madurez fisiológica, luego comienzan a cambiar de color en forma gradual, alcanzando su color definitivo algunos días después de ocurrida la madurez. 
La maduración ocurre en forma bastante desconcentrada: en una misma planta es posible encontrar granos que sobrepasan la madurez fisiológica en un nivel basal y granos verdes en un nivel alto de ramificación. Este es el punto débil que tiene esta leguminosa, ya que al esperar que la madurez de trilla se logre en la mayor cantidad de niveles de la planta, es frecuente que se produzca algún grado de dehiscencia natural o desgrane por acción de la trilladora en el primer nivel de ramificación.

El chocho tiene diversas formas de utilización. Por ejemplo, para el consumo humano se puede presentar fresco desamargado para utilizar en guisos, purés, salsas, cebiche serrano, sopas (crema de tarwi); guisos (pepián), postres (mazamorras con naranja) y refrescos (jugo de papaya con harina de tarwi).

Industrialmente, la harina de esta leguminosa se utiliza hasta en $15 \%$ en la panificación, por la ventaja de mejorar considerablemente el valor proteico y calórico del producto. De igual forma, tiene uso medicinal: los alcaloides (esparteína, lupinina, lupanidina, etcétera) se emplean para controlar ectoparásitos y parásitos intestinales de los animales.

Asimismo, su uso agronómico incluye que en estado de floración la planta se incorpora a la tierra como abono verde, con buenos resultados, mejorando la cantidad de materia orgánica, estructura y retención de humedad del suelo. Finalmente, los residuos de la cosecha (tallos secos) se usan como combustible por la gran cantidad de celulosa que proporciona un buen poder calorífico.

\subsection{Producción, insumos y comercialización}

En el gráfico se puede apreciar una típica campaña agrícola de los dos cultivos materia de este estudio. 


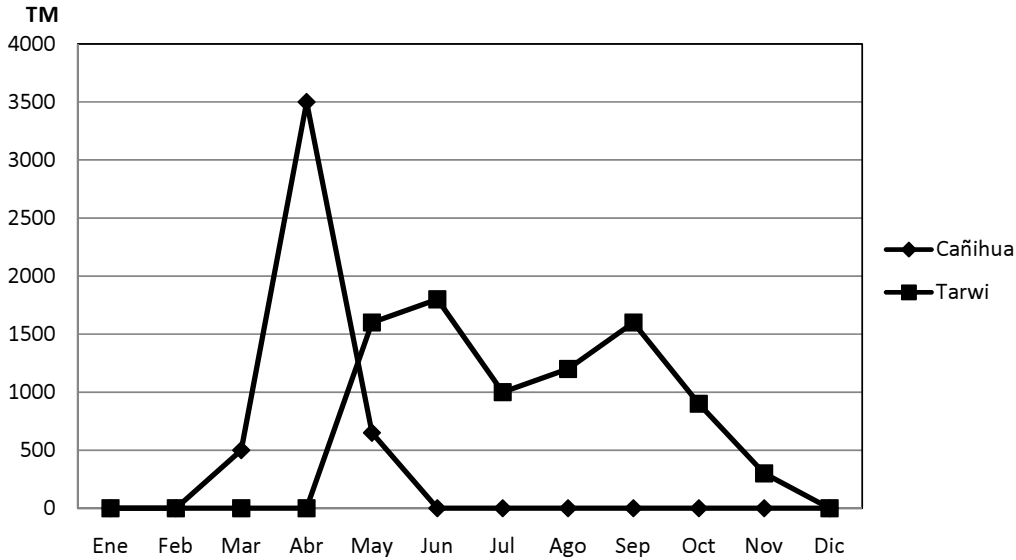

El mercado de los cultivos andinos, como la cañihua y el tarwi, se caracteriza por la presencia de un gran número de intermediarios que originan una variada gama de modalidades de comercialización que distorsionan los precios (el cliente final podría ver incrementado el precio del producto hasta en 60\%). De esta manera, el precio al que estaría adquiriendo los granos de cañihua es de S/.1.93 el kilo (precio en mercado o feria [katos, en quechua]). El tarwi, por su parte, se consigue en los mercadillos a S/.1.50 el kilo.

El proyecto hará uso también de otros insumos para producir el extruido; estos se encuentran en abundancia en el mercado local, por lo que no significarían una limitación al desarrollo del proyecto. Entre ellos, la harina de lúcuma, que actuará como saborizante natural, se puede conseguir a S/.5.80 el kilo y los costos de los demás materiales requeridos para formar la mezcla, tales como el aceite esencial de muña (preservante natural), sal y edulcorante, suman en conjunto S/.4.50 el kilo.

\section{LA PLANTA INDUSTRIAL}

\subsection{Localización de la planta}

Se determinó que los factores predominantes para el proyecto son los siguientes: 
- Disponibilidad de materias primas.

- Cercanía a puerto de embarque marítimo.

- Requerimiento de infraestructura industrial.

Sobre esta base se definió que las localidades por evaluar serían Lima, Arequipa y Cusco.

Luego de realizar el análisis de macrolocalización, Arequipa resultó la región más indicada para construir la planta. Las fortalezas principales de este departamento son su proximidad a las materias primas, su clima seco y fresco (lo cual ayudará en el proceso de secado), y su infraestructura industrial, con muy buenas condiciones físicas y una gran disponibilidad de mano de obra.

En el nivel de microlocalización se plantearon como factores principales la disponibilidad de terrenos y sus costos, las vías de acceso y los efectos sobre el medio ambiente. Se evaluaron dos parques industriales: el emergente Río Seco y el tradicional El Palomar, imponiéndose el primero por un $69 \%$ sobre el segundo.

El Parque Industrial de Río Seco (PIRS) se ubica en el distrito de Cerro Colorado, a $12 \mathrm{~km}$ al noreste de la ciudad de Arequipa, muy próximo al Aeropuerto Internacional Rodríguez Ballón, a una altitud aproximada de 2.400 metros. En este parque industrial existe terreno disponible para la adquisición y construcción de nuevas plantas o locales a un costo relativamente bajo.

\subsection{Tamaño de la planta}

El tamaño de la planta (200 kg por t/h) se determinó sobre la base de la tecnología, que resultó ser el factor limitante; específicamente la estación de cocción-extrusión, etapa fundamental del proceso de producción, que se convierte en el "cuello de botella" debido a su capacidad de procesamiento.

A modo referencial, se calculó el tamaño mínimo que hará viable el proyecto a través del punto de equilibrio, estableciéndose en $4,03 \mathrm{~kg}$ por $\mathrm{t} / \mathrm{h}$. 


\section{INGENIERÍA DEL PROYECTO}

\subsection{Especificaciones técnicas del producto}

En el cuadro se puede observar la ficha técnica del producto por ofrecer:

\section{Cuadro 6}

Ficha técnica de un envase $(22 \mathrm{~g})$ de cereal listo para consumir

Nombre del producto

Descripción

Composición

Características

organolépticas

\section{Características}

físicoquímicas/

información nutricional
Extruido de una mezcla nutritiva en base a cañihua y tarwi

Es un cereal orgánico-funcional frío listo para ser consumido, con alto valor proteínico y totalmente inocuo para la salud humana.

\begin{tabular}{lr}
\multicolumn{2}{c}{ Porcentaje en peso (\%) } \\
Cañihua & 33 \\
Tarwi & 33 \\
Agua & 24 \\
Harina de lúcuma & 5 \\
Aceite esencial de muña (preservante orgánico) & 1 \\
Sal & 2 \\
Edulcorante & 2 \\
& \\
Sabor característico de la lúcuma, libre de sabor extraño \\
rancio, tostado) \\
Color beige \\
Textura porosa
\end{tabular}

Porcentaje (\%)

$\begin{array}{lr}\text { Humedad } & 4 \\ \text { Proteínas }(\mathrm{N} \times 6.25) & 14 \\ \text { Grasa } & 12 \\ \text { Fibra } & 5 \\ \text { Carbohidratos } & 55 \\ \text { Vitaminas } & 6 \\ \text { Minerales } & 4 \\ \text { Energía total (Kcal/porción: porción = 22 g) } & 100\end{array}$

(continúa) 
Bruno H. Weitz Perl

(continuación)

Consumidores potenciales

Empaque $y$

presentaciones

Vida útil

Condiciones de manejo y conservación
Destinado principalmente al consumo de niños de acuerdo con sus requerimientos nutricionales y de ingesta diaria. Igualmente, ideal para el consumo de adultos.

Envase de polietileno opaco de alta densidad de 3.5 milésimas de pulgada de espesor y sellado herméticamente al calor. Presentación de 22 gramos.

Seis meses a partir de la fecha de producción, siempre y cuando se mantenga en las condiciones de almacenamiento adecuadas.

Almacenamiento en un lugar cerrado, seco y ventilado. Debe mantenerse en condiciones sanitarias, libre de olores extraños, de plagas, etcétera.

Fuente: FAO/OMS.

\subsection{Naturaleza de la tecnología requerida}

La extrusión en el sector alimenticio es un proceso termodinámico de cocido y secado de alta temperatura en corto tiempo (HTST, por sus siglas en inglés) mediante el cual la harina se expande y adquiere una consistencia plástica en un tubo por combinación de presión y temperatura. Esta tecnología permite una cocción uniforme, y la esterilización y retención de las proteínas y aminoácidos de los alimentos que son sometidos a este proceso, siendo bien aceptada por el consumidor. Como beneficios directos, además de mejorar la funcionalidad de los productos procesados, facilita la absorción biológica de sus nutrientes y asegura en ellos valores prácticamente nulos de contaminación microbiológica. Sin embargo, lo realmente importante es que el proceso se va dando sin deformar o modificar las características propias de los insumos originales.

El material que alimenta a una extrusora contiene entre $12 \%$ y $20 \%$ de humedad y el producto obtenido queda con un rango entre $8 \%$ 
y 15\%; es decir, la ventaja principal de la cocción-extrusión es que se pueden trabajar masas con grados de humedad relativamente bajos, lo que reduce drásticamente los costos de producción, dado que el volumen de agua que se eliminará luego, es relativamente bajo si se le compara con la cantidad que queda después de la cocción con otra tecnología.

Desde el punto de vista económico, se trata de un proceso rápido, de reducida superficie requerida para la producción y de rápida respuesta, lo que implica bajos costos.

Otro atractivo de esta tecnología es su flexibilidad, pues da la posibilidad de aumentar la gama de productos, variando las formas, las texturas y los colores y sabores de las materias primas. De igual modo, la cocción-extrusión mejora la apariencia, la palatabilidad y la digestibilidad de los productos finales y, quizás lo más importante, retiene las proteínas y aminoácidos que contienen las materias primas.

Cabe resaltar que en muchos casos la extrusora determina, entre otras cosas, el tamaño de partícula de las materias primas ingresantes, su contenido de grasa mínimo y máximo, y la cantidad de almidón total mínima que debe ingresar para que se forme la masa.

\subsection{Proceso de producción}

La producción del extruido de este proyecto es semiautomática; es decir, existe cierto grado de manipuleo por parte de los operarios de la planta en y entre las distintas operaciones que comprende todo el proceso.

Cabe destacar que, al tratarse de un producto alimenticio, es importante velar por la calidad en la producción. Por lo tanto, se hará uso del sistema HACCP (Hazard Analysis \& Critical Control Points), ejerciendo un constante análisis de riesgos y cuidando los puntos críticos de control identificados en el proceso.

El proceso de producción se resume gráficamente en el siguiente diagrama de bloques: 
Bruno H. Weitz Perl

Figura 1

Diagrama de bloques del proceso de producción
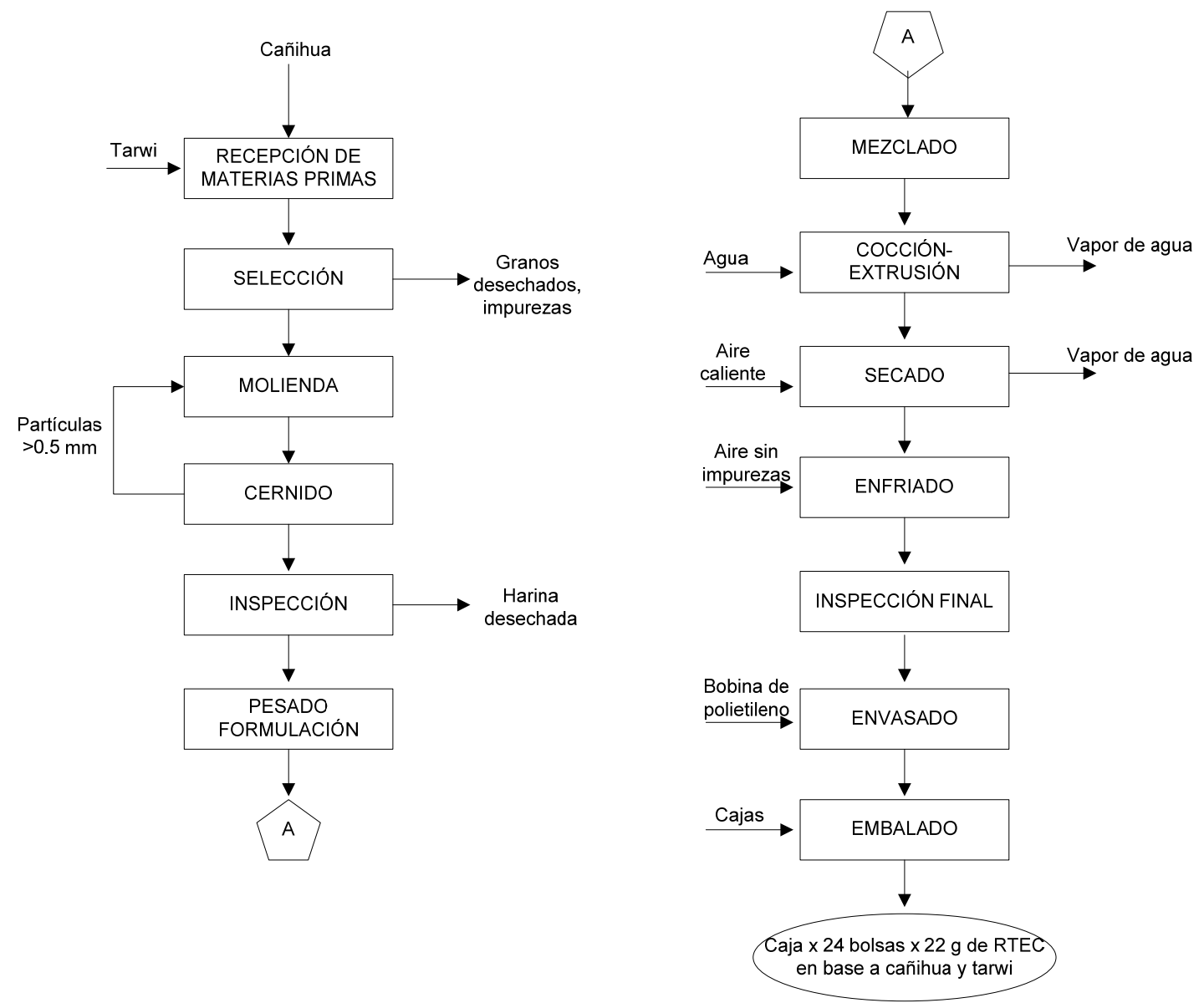

\subsection{Maquinaria y equipo}

La relación de la maquinaria necesaria para la producción del extruido se resume a continuación: 
Cuadro 7

Máquinas y equipos necesarios para el proyecto

\begin{tabular}{ll}
\hline Operación/Actividad & \multicolumn{1}{c}{ Máquina/Equipo } \\
\hline Molienda & Molino de martillos para granos \\
Cernido & Tamizadora \\
Formulación & Balanza industrial \\
Mezclado & Mezcladora horizontal de cintas \\
Cocción & Extrusora de un tornillo \\
Secado & Secador horizontal \\
Enfriado & Enfriador \\
Envasado & Envasadora al vacío \\
\hline
\end{tabular}

La extrusora llevará el ritmo de la producción, pues es la máquina fundamental de la cual depende todo el proceso; por ello, la capacidad instalada teórica de la planta está determinada en $200 \mathrm{~kg} / \mathrm{h} .{ }^{6}$

El personal estará lo suficientemente preparado para no disminuir esta capacidad de producción.

\subsection{Resguardo de la calidad}

La calidad del producto deberá garantizarse a lo largo de todo el proceso de producción.

Así, la materia prima deberá cumplir con los requerimientos físicos, químicos, microbiológicos, higiénicos y sanitarios que determinan las Normas Técnicas Peruanas (NTP) 205.036 y 205.056 para la cañihua y el tarwi, respectivamente, así como las características solicitadas por las certificaciones orgánicas, las cuales reflejarán los requerimientos de los mercados objetivo.

De igual modo, debe existir un estricto control de variables tales como temperatura, presión, humedad, nivel de $\mathrm{pH}$, entre otros, en las diversas etapas de la transformación de materias primas e insumos. El departamento de producción publicará y mantendrá actualizadas las

6 No obstante, por recomendación de los fabricantes de la máquina debería considerarse una capacidad real del $95 \%$. Por lo tanto, el flujo másico que deberá pasar por todas las máquinas para poder obtener el extruido será de $190 \mathrm{~kg} / \mathrm{h}$, lo cual cambiaría el tamaño de planta calculado con anterioridad. 
especificaciones técnicas que establezcan claramente los estándares del producto y el proceso, que deberá ser compartido con todo el personal de planta.

Como se mencionó, la calidad en la producción estará controlada mediante la utilización del sistema HACCP, ejerciendo un constante análisis de riesgos y cuidando los puntos críticos de control identificados en el proceso. El objetivo es garantizar un producto completamente inocuo para el consumo humano, cuidando todas las operaciones por donde pasa la materia prima que se transforma, así como manteniendo limpios los ambientes apropiados para asegurar la inocuidad de los alimentos producidos.

Finalmente, al tratarse de un alimento proteínico, el valor nutritivo o la calidad de una proteína es útil para establecer la capacidad para satisfacer las necesidades del organismo. La calidad del producto, por lo tanto, viene determinada por varias de las características de las mismas proteínas. Entre ellas, se evaluará la digestibilidad, el valor biológico y la utilización proteínica neta (UPN).

\section{ASPECTOS ECONÓMICOS}

\subsection{Inversión}

El proyecto requerirá una inversión inicial ascendente a US $\$ 188.719$. El $60 \%$ de este monto estará destinado a la adquisición de la maquinaria y el equipo necesario para la operación de la planta, así como a los trabajos de edificación, y el $20 \%$ se reservará para el capital de trabajo. Este último comprende los recursos que requerirá la empresa para la realización normal de actividades durante su primer ciclo productivo (que se calcula tendrá un mes de duración); con ello, podrá hacerle frente a los problemas de liquidez a corto plazo, hasta que se cobre el dinero proveniente de la venta del producto.

El detalle de la inversión inicial requerida para este proyecto es el siguiente: 
Cuadro 8

Inversión inicial para el proyecto

\begin{tabular}{lrr}
\hline Descripción & Monto (US\$) & \multicolumn{1}{c}{$\%$} \\
\hline Inversión fija intangible & 17.270 & $\mathbf{9 , 1 5}$ \\
Estudios del proyecto & 5.000 & 2,65 \\
Gastos constitución de la empresa & 6.000 & 3,18 \\
Gastos implementación del proyecto & 3.500 & 1,85 \\
Gastos puesta en marcha & 1.200 & 0,64 \\
Imprevistos (10\% de las inv. intangibles) & 1.570 & 0,83 \\
Inversión fija tangible & 133.185 & 70,57 \\
Terreno & 6.600 & 3,50 \\
Edificaciones & 62.713 & 33,23 \\
Máquinas y equipos de producción & 50.589 & 26,81 \\
Equipos de oficina & 4.570 & 2,42 \\
Imprevistos (7\% de las inv. tangibles) & 8.714 & 4,62 \\
Capital de trabajo & 38.264 & $\mathbf{2 0 , 2 8}$ \\
Materiales e insumos & 21.514 & 11,40 \\
Mano de obra & 9.639 & 5,11 \\
Consumo de energía eléctrica & 60 & 0,03 \\
Consumo gas & 4.988 & 2,64 \\
Suministro de agua & 13 & 0,01 \\
Consumo telefónico & 300 & 0,16 \\
Servicio trámites para la exportación & 1.000 & 0,53 \\
Imprevistos (2\% de la inv. en costo de capital) & 750 & 0,40 \\
TOTAL INVERSIONES & 188.719 & 100 \\
\hline
\end{tabular}

\section{IMPACTO SOCIAL}

Este proyecto impacta positivamente en la sociedad y no causa efectos negativos sobre el medio ambiente.

En cuanto a la tecnología, está íntimamente relacionada con el progreso y el desarrollo humano, ya sea mediante ella o a partir de ella.

Por un lado, esta eleva de modo directo la capacidad humana: muchos productos mejoran directamente la salud, la nutrición, los conocimientos y los niveles de vida de las personas y aumentan sus posibilidades de participar más activamente en la vida social, económica y política de la comunidad. Al mismo tiempo, el desarrollo humano es un medio importante para alcanzar el desarrollo tecnológico. Las innovaciones tecnológicas son una expresión de la potencialidad humana: mientras más elevados sean los niveles de educación, más notable será la contribución a la creación y difusión de la tecnología. 
Adicionalmente, cabe mencionar que la competitividad, en el plano del desarrollo humano, asocia la competencia y el aumento de la productividad con el progreso de las personas como individuos y el de los territorios en donde se desempeñan.

Se debe enfatizar en el establecimiento de metas de empleo y productividad creciente. Para lograr este objetivo, se requiere maximizar el uso de las potencialidades (recursos no explotados, inadecuadamente explotados o insuficientemente explotados) y establecer lo que se denomina "competitividad en cadena". Esta permite ir más allá de la diversificación y la especialización, y plantear dosis o combinaciones de ambas en función de las diversas realidades del país, partiendo desde las localidades más pequeñas y aisladas hacia el núcleo moderno nacional (la capital).

La competitividad en cadena implica una división del trabajo que aprovecha en escala creciente los diferentes factores y las potencialidades de cada región o localidad. Esta tiene un impacto dinamizador que permite la incorporación de cada vez más unidades productivas de diferente escala y su ubicación en los variados mercados nacionales e internacionales en función de sus niveles de competencia.

Aquí cabe detenerse para revisar la inversión que realiza el Perú en salud, educación y en investigación y desarrollo (I\&D).

Según el Informe sobre Desarrollo Humano publicado por el Programa de las Naciones Unidas para el Desarrollo (PNUD), ${ }^{7}$ el Perú se encuentra entre los países con un desarrollo humano medio en el puesto 87, con un indicador de 0.773 (versus el 0.968 de Islandia, el primer puesto en la lista). El gasto público en salud representa un ínfimo 1,9\% del PBI, mientras que el privado alcanza el 2,2\% (en los países con índices altos de desarrollo humano, ambas cifras suman el 10\% de su PBI). De igual modo, el gasto público en educación en el Perú representa menos de la mitad de lo que mínimamente consideran los países desarrollados, siendo 2,4\% del PBI lo destinado a este fin (la mitad se invierte en educación primaria y tan sólo un $11 \%$ en educación superior). Finalmente, el Gobierno peruano invierte solo el $0,1 \%$ de su PBI en I\&D,

7 Informe sobre Desarrollo Humano 2007-2008. La lucha contra el cambio climático: Solidaridad frente a un mundo dividido, 2008.

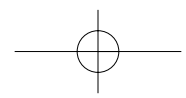


mientras los primeros países lo hacen en alrededor del 3\%. La inversión en I\&D en el Perú no solo es mínima sino que se constata una significativa reducción a lo largo de las últimas tres décadas, puesto que en 1975 este indicador ascendía a 0,36\% del PBI.

Por lo mencionado en líneas anteriores, al ofrecer más y mejores puestos de trabajo con la eventual realización del presente proyecto, tanto directa (agricultores, operarios, supervisores, gerentes, etcétera) como indirectamente (como es el caso de los que trabajan en el ámbito del comercio exterior), se estaría contribuyendo a elevar el nivel de vida mediante el pago de sueldos y salarios justos, acordes con la labor digna que desempeñan las personas.

Asimismo, y en línea con lo anterior, existe la oportunidad de explotar la orientación actual del consumidor del primer mundo por comprar productos inclusivos y de comercio justo, pautas que este proyecto no dudará en cumplir.

\section{CONCLUSIONES}

1. La extrusión es una de las tecnologías más versátiles que existen en la actualidad. Además de permitir el procesamiento de diversas materias primas y obtener variados productos tan solo con variar la matriz al final, es excelente para eliminar las sustancias antinutrientes y tóxicas de la leguminosa (en este caso, del tarwi) y gelificar el almidón de los cereales, lo cual aumenta la digestibilidad del producto.

2. Sería oportuno aprovechar el auge que tienen los productos orgánicos y funcionales en los países desarrollados, donde la demanda es creciente. Por ello, se desea ofrecer una atractiva alternativa basada en alimentos netamente peruanos, lo que conllevaría la promoción de la cultura del país en el extranjero.

3. Como se trata de un producto de conveniencia, es de suma importancia que el producto esté dónde y cuándo se requiera. Para ello, se deberá gestionar una eficiente administración de la cadena de suministro (si se puede implementar una tecnología SCM, mejor aún), en el que adquiera especial importancia la distribución.

4. En línea con lo anterior, un producto de esas características puede ser sustituido fácilmente por otro. La idea sería fidelizar a los clientes más rentables ofreciéndoles productos innovadores de calidad 
(por ejemplo, considerar darle sabor a la mezcla con harina de otras frutas oriundas, tales como la chirimoya, la granadilla, la guanábana, etcétera, alternativamente a la harina de lúcuma).

\section{RECOMENDACIONES}

1. Considerar mezclas alternativas para las épocas de desabastecimiento de materias primas.

2. Evaluar la introducción del producto propuesto en los mercados local y regional en el mediano plazo. Previamente, mediante una campaña de concientización social (impulsada en conjunto por los sectores público y privado), deberán cambiarse en forma paulatina los hábitos de consumo de los peruanos y después los de los latinoamericanos.

3. Es necesario que los sectores privado y público promuevan intensivamente la reconversión de cultivos agrícolas por productos en los que el Perú tenga ventajas comparativas. Así, se deberá optar por certificar más hectáreas orgánicas, ir dejando de lado el cultivo de trigo y de arroz, por ejemplo, ya que en el marco de la globalización y de los tratados comerciales de libre comercio suscritos por el Perú, sería inútil competir con países que poseen ventajas en esos rubros.

4. Los inversionistas deberían seguir apoyando la tendencia exportadora de productos no tradicionales, ya que por su valor agregado, como el que se propone en este estudio, constituyen una fuente importante de ingreso de divisas al país, así como una provisión de trabajo digno a miles de personas.

5. Organizándose eficientemente, las pequeñas y medianas empresas podrían potenciar en gran medida la economía nacional. Con el apoyo del gobierno, estas podrían formar sociedades y, como una sola fuerza, exportar sus productos. 


\section{BIBLIOGRAFÍA}

Alvídrez, Alicia; González, Blanca; Jiménez, Zacarías. "Tendencias en la producción de alimentos: Alimentos funcionales" [en línea]. $<$ http://www.uanl.mx/publicaciones/respyn/iii/3/index.html>.

Bio Latina Certificadora Latinoamericana [en línea]. <http://www.biolatina.com/>.

Casino, Gonzalo. "Comida o medicina" [en línea]. <http://nutriguia.com/ ?t=TOPIC;topic=art-arch>.

Díaz Garay, Bertha; Jarufe Zedán, Benjamín y María Teresa Noriega Araníbar. Disposición de planta. 2. a edición. Lima: Universidad de Lima, 2007.

Dirección General de Estadística y Censos de El Salvador. "Clasificadores Internacionales" [en línea]. <http://www.digestyc.gob.sv>.

Facultad de Farmacia y Bioquímica de la Universidad de Buenos Aires. "La importancia de los minerales en la nutrición" [en línea]. <http://www.elsantafesino.com/vida/2006/02/17/4275>.

Guerra Miranda, Miriam Isabel. "Estudio tecnológico para la elaboración de una mezcla proteica a base de cañihua". Lima: Universidad de Lima, 1996.

Kotler, Phillip. Fundamentos del Marketing. México: Pearson Education, 2003.

Levy Rubinger, Felipe Mauricio. "Estudio de prefactibilidad para la implementación de una fábrica de ataúdes de cartón corrugado". Tesis para optar el título de Ingeniero Industrial. Lima: Universidad de Lima, 2004.

Llorente, José Ramón. "La importancia del fósforo" [en línea]. <www. dsalud.com/medicinaorto_numero28_\%20b.htm>.

Martínez, Yaiza. 'La alimentación saludable y 'para llevar' se impone en el mercado global" [en línea]. <http://www.tendencias21.net/TENDENCIAS-SOCIALES_r6.html>.

Ministerio de Comercio Exterior y Turismo. "Arancel de Aduanas del Perú" [en línea]. <http://www.mincetur.gob.pe/COMERCIO/ leyes/Arancel/s. 
Organización de las Naciones Unidas para la Agricultura y la Alimentación. "Balances de Alimentarios" [en línea]. <http://faostat.fao.org/ site/354/default.aspx>.

Organización de las Naciones Unidas para la Agricultura y la Alimentación. "Producción" [en línea]. <http://faostat.fao.org/site/339/ default.aspx>.

Programa de las Naciones Unidas para el Desarrollo. Informe sobre Desarrollo Humano 2007-2008. La lucha contra el cambio climático: Solidaridad frente a un mundo dividido. Ohio: PNUD, 2008.

Salas Choque, Wilson Alejandro. Aplicación del sistema HACCP en el proceso de elaboración de alimentos de reconstitución instantánea a base de cereales extruidos. Lima: Universidad Nacional Mayor de San Marcos, 2009

Sayre, Laura. "Euroganics-Organics in Europe". The Natural Farmer Spring, vol. 2, núm. 68, 2006 [en línea]. <http://www.organicconsumers.org/2006/article_418.cfm>.

Superintendencia Nacional de Administración Tributaria (Sunat)-Aduanas. "Preguntas frecuentes de exportación" [en línea]. $<$ http://www.aduanet.gob.pe/aduanas/informag/exportac.htm>. 